\title{
Synthesis and Evaluation of Polyhydroxylated Near-Infrared Carbocyanine Molecular Probes
}

\author{
Zongren Zhang and Samuel Achilefu* \\ Department of Radiology, Washington University, St. Louis, Missouri 63110 \\ Email Address: achilefus@.wustl.edu
}

\section{$\underline{\text { S1. Synthetic procedures }}$}

General. Reagents and solvents were purchased from commercial source. THF was distilled after refluxing in sodium for two days. Reactions were monitored by either HPLC with UV monitor, TLC with visual observation of the dye spots or mass spectrometry. Product purification was made by silica gel column, C-18 reverse phase column and/or semi-preparative HPLC. Product purity was established when a single HPLC peak and single MS peak were obtained. MS were performed on a ZQ4000 Mass Spectrometry. Absorption spectra were recorded on Beckman Coulter DU 640 UV-Vis spectrometer. Fluorescent emission spectra were recorded on a Jobin Yvon-Spex Fluorolog-3 spectrofluorometer.

1-Hydroxycarbonylethyl-2,3,3-trimethylbenzoindoleninium bromide (5). 2,3,3Trimethylbenzoindolenine $(5.81 \mathrm{~g}, 27.8 \mathrm{mmol})$ and 3-bromopropionic acid (4.23 g, $27.7 \mathrm{mmol})$ were dissolved in 1,2-dichlorobenzene $(80 \mathrm{~mL})$. The mixture was stirred at $100{ }^{\circ} \mathrm{C}$ for $20 \mathrm{~h}$ leading to needle like crystals. The reaction was cooled to room temperature. Product was filtered, washed with ether and dried to give $9.05 \mathrm{~g}(90 \%)$ of 5 as a solid. ${ }^{1} \mathrm{H}$ NMR (DMSO, $\left.300 \mathrm{MHz}\right): \delta 8.36(\mathrm{~d}, J=8.4 \mathrm{~Hz}, 1 \mathrm{H}), 8.28$ $(\mathrm{d}, J=10.8 \mathrm{~Hz}, 1 \mathrm{H}), 8.22(\mathrm{~d}, J=8.4 \mathrm{~Hz}, 1 \mathrm{H}), 8.16(\mathrm{~d}, J=10.8 \mathrm{~Hz}, 1 \mathrm{H}), 7.78-7.72(\mathrm{~m}, 2 \mathrm{H}), 4.77(\mathrm{t}, J=$ $6.9 \mathrm{~Hz}, 2 \mathrm{H}), 3.52$ (br, 1H), $3.04(\mathrm{t}, J=6.9 \mathrm{~Hz}, 2 \mathrm{H}), 2.97(\mathrm{~s}, 3 \mathrm{H}), 1.75(\mathrm{~s}, 6 \mathrm{H})$.

2-Chloro-1-formyl-3-(hydroxymethylene)cyclohex-1-ene (7). A solution of $\mathrm{POCl}_{3}(37 \mathrm{~mL}$, $397 \mathrm{mmol})$ in DCM (35 mL) was slowly added to an ice-cooled solution of DMF (40 mL, $516 \mathrm{mmol})$ in DCM (40 mL). After the addition was finished, cyclohexanone (10 g, $100 \mathrm{mmol})$ was added in via syringe. The resulted reaction mixture was refluxed for $2 \mathrm{~h}$. The mixture was then cooled in ice. Water $(200 \mathrm{~mL})$, pre-cooled to $0^{\circ} \mathrm{C}$ was added slowly while the mixture was stirred. The mixture was stirred for 30 min. DCM layer was collected and the water layer was extracted with additional DCM. The DCM solutions were combined, passed through a $\mathrm{MgSO}_{4}$ column, concentrated on a rotavapor and treated with pentane $(200 \mathrm{~mL})$ to give $4.68 \mathrm{~g}(27 \%)$ of 7 as yellow crystalline solid.

Di-n-butyl CCC (8). Into a flask attached with Dean-Stark trap and a condenser were added 1hydroxycarbonylethyl-2,3,3-trimethylbenzoindoleninium bromide 5 (14.43 g, $39.83 \mathrm{mmol})$, freshly prepared 2-chloro-1-formyl-3-(hydroxymethylene)cyclohex-1-ene 7 (3.42 g, 20 mmol), n-butanol (300 $\mathrm{mL})$ and benzene $(30 \mathrm{~mL})$. The mixture was refluxed for $15 \mathrm{~h}$ to give dark green solution. Solvents were removed on a rotavapor. Residue was washed with hexane/EtOAc and eluted with DCM/MeOH from a silica gel plug to give the crude product. Further chromatography on a silica gel column with gradient Hexane/EtOAc-DCM/MeOH solvent system led to $12.35 \mathrm{~g}(89 \%)$ of $\mathbf{8}$ as dark green solid. ${ }^{1} \mathrm{H}$ NMR (DMSO, $300 \mathrm{MHz}): \delta 8.36(\mathrm{~d}, J=14.1 \mathrm{~Hz}, 2 \mathrm{H}), 8.28(\mathrm{~d}, J=9.0 \mathrm{~Hz}, 2 \mathrm{H}), 8.07(\mathrm{~m}, 4 \mathrm{H}), 7.77(\mathrm{~d}, J=9.0 \mathrm{~Hz}$, 2H), $7.63(\mathrm{~m}, 2 \mathrm{H}), 7.51(\mathrm{~m}, 2 \mathrm{H}), 6.43$ (d, J=14.4 Hz, 2H), 4.64 (bt, 4H), 3.94 (t, J=6.6 Hz, 4H), 2.91 (t, 
$J=6.3 \mathrm{~Hz}, 4 \mathrm{H}), 2.76(\mathrm{bt}, 4 \mathrm{H}), 1.93(\mathrm{~s}, 12 \mathrm{H}), 1.86(\mathrm{~m}, 2 \mathrm{H}), 1.40(\mathrm{~m}, 4 \mathrm{H}), 1.17(\mathrm{~m}, 4 \mathrm{H}), 0.73$ (t, $J=7.2 \mathrm{~Hz}$, 6H). MS/EI: $811\left(\mathrm{M}^{+}\right)$; HPLC (aqueous MeCN with 1\% TFA: 50\%-5 min-70\%-40min-95\%-2 min50\%-3 $\min -50 \%): 33 \mathrm{~min}$.

Acetonide protected CCG (11). Into an argon-flushed, dry ice-cooled flask were added 1,2:3,4di- $O$-isopropylidene-D-galactopyranose $(1.0139 \mathrm{~g}, 3.89 \mathrm{mmol})$ and THF (anhydrous, $20 \mathrm{~mL}$ ). The flask was then sealed with rubber septum and $t$-BuLi $(1.7 \mathrm{M}$ in pentane, $2.3 \mathrm{~mL}, 3.90 \mathrm{mmol})$ was added via syringe. The resulting mixture was stirred for additional $30 \mathrm{~min}$ and transferred into a dry ice-cooled THF $(20 \mathrm{~mL})$ solution of di- $n$-butyl CCC $8(0.6053 \mathrm{~g}, 0.87 \mathrm{mmol})$. The mixture was then stirred for $5 \mathrm{~h}$ at room temperature and neutralized with hydrobromic acid. THF was removed. The solid residue was washed with water and dried in vacuum to give crude $\mathbf{1 1}$ as essentially a mixture of $\mathbf{1 1}$ and mono- $n$ butyl protected CCC. Separation of the two was made either on a pressurized C-18 column or semipreparative HPLC with aqueous acetonitrile as eluent to give $0.30 \mathrm{~g}(37 \%)$ of $\mathbf{1 1}$ as dark green solid. MS/EI: $941\left(\mathrm{M}^{+}+\mathrm{H}_{2} \mathrm{O}\right)$; HPLC (aqueous MeCN with 1\%TFA: 10\%-5 min-70\%-15 min-100\%-10 $\min -10 \%): 18.5 \mathrm{~min}$.

\section{$\operatorname{CCC}(9)$.}

Method A: To a THF $(20 \mathrm{~mL})$ solution of $t$-BuONa $(0.544 \mathrm{~g}, 5.67 \mathrm{mmol})$ was added di- $n$-butyl CCC 8 (1.2705 g, $1.57 \mathrm{mmol})$ in solid form. The resulting mixture was stirred at room temperature for $24 \mathrm{~h}$ and treated with ether to precipitate the product. The compound was eluted on a silica gel column with sequential increase of $\mathrm{MeOH}$ in $\mathrm{DCM} / \mathrm{EtOAc}$ to give $0.88 \mathrm{~g}(80 \%)$ of 9 as green solid. ${ }^{1} \mathrm{H}$ NMR (DMSO, $300 \mathrm{MHz}$ ): $\delta 8.37$ (d, $J=14.1 \mathrm{~Hz}, 2 \mathrm{H}), 8.30(\mathrm{~d}, J=8.4 \mathrm{~Hz}, 2 \mathrm{H}), 8.08(\mathrm{~m}, 4 \mathrm{H}), 7.78(\mathrm{~d}, J=9.0 \mathrm{~Hz}$, 2H), $7.66(\mathrm{~m}, 2 \mathrm{H}), 7.52(\mathrm{~m}, 2 \mathrm{H}), 6.48(\mathrm{~d}, J=14.4 \mathrm{~Hz}, 2 \mathrm{H}), 4.58$ (bt, 4H), 2.87-2.76 (m, 8H), 2.02-1.84 $(\mathrm{m}, 14 \mathrm{H})$. MS/EI $699\left(\mathrm{M}^{+}\right)$; HPLC (aqueous MeCN with 1\% TFA: 10\%-5min-80\%-15min-100\%-10 $\min -10 \%): 12.5 \mathrm{~min}$.

Method B: CCC was also made following the same procedure as described in di- $n$-Bu CCC synthesis with the temperature controlled between 100 and $105^{\circ} \mathrm{C}$ and the reaction was stopped as soon as the reaction mixture turned into green. The crude product obtained was purified as described in Method A above to give pure CCC.

CCG (2). A TFA (2 mL) solution of acetonide protected CCG $11(57 \mathrm{mg}, 61 \mu \mathrm{mol})$ was stirred at room temperature for $3 \mathrm{~h}$. TFA was removed via air blowing and residue was subjected to preparative HPLC eluded with aqueous MeCN with 1\%TFA (65\%-100 min- $90 \%, 5 \mathrm{~mL} / \mathrm{min})$ to give $22 \mathrm{mg}(43 \%)$ of 2 as green solid. MS/EI $861\left(\mathrm{M}^{+}+\mathrm{H}_{2} \mathrm{O}\right)$; HPLC (aqueous MeCN with 1\%TFA: 10\%-5 min-60\%-15 min-90\%-10 min-10\%): 17 min.

\section{$\underline{\text { S2. Absorption and fluorescence study }}$}

Dye solutions were prepared by weighing calculated amounts $(0.50 \mathrm{mg}$ scale) of dye samples on an analytical balance (accuracy $\pm 0.01 \mathrm{mg}$ ) directly into a container and dissolved in a specified volume DMSO. The DMSO solutions were diluted with $\mathrm{H}_{2} \mathrm{O}$ to give the stock solution $\left(10^{-5} \mathrm{M}\right)$ as $20 \%$ DMSO in water. Desired concentrations of the probes were obtained by further dilution of the stock solution with $20 \%$ DMSO in water. 


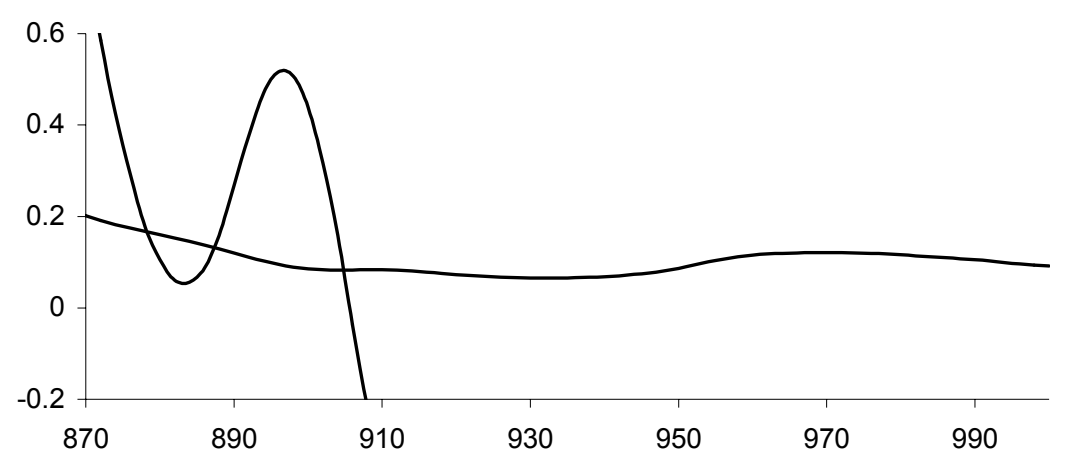

UV absorptions of CCG 2 (flattened) and $n$-butyl protected CCC 8 (curved) at 870-1000 nm region at the same concentration $\left(3.0 \times 10^{-6} \mathrm{M}\right)$

\section{$\underline{\text { S3. MS/EI of di- } n \text {-butyl CCC (8) }}$}

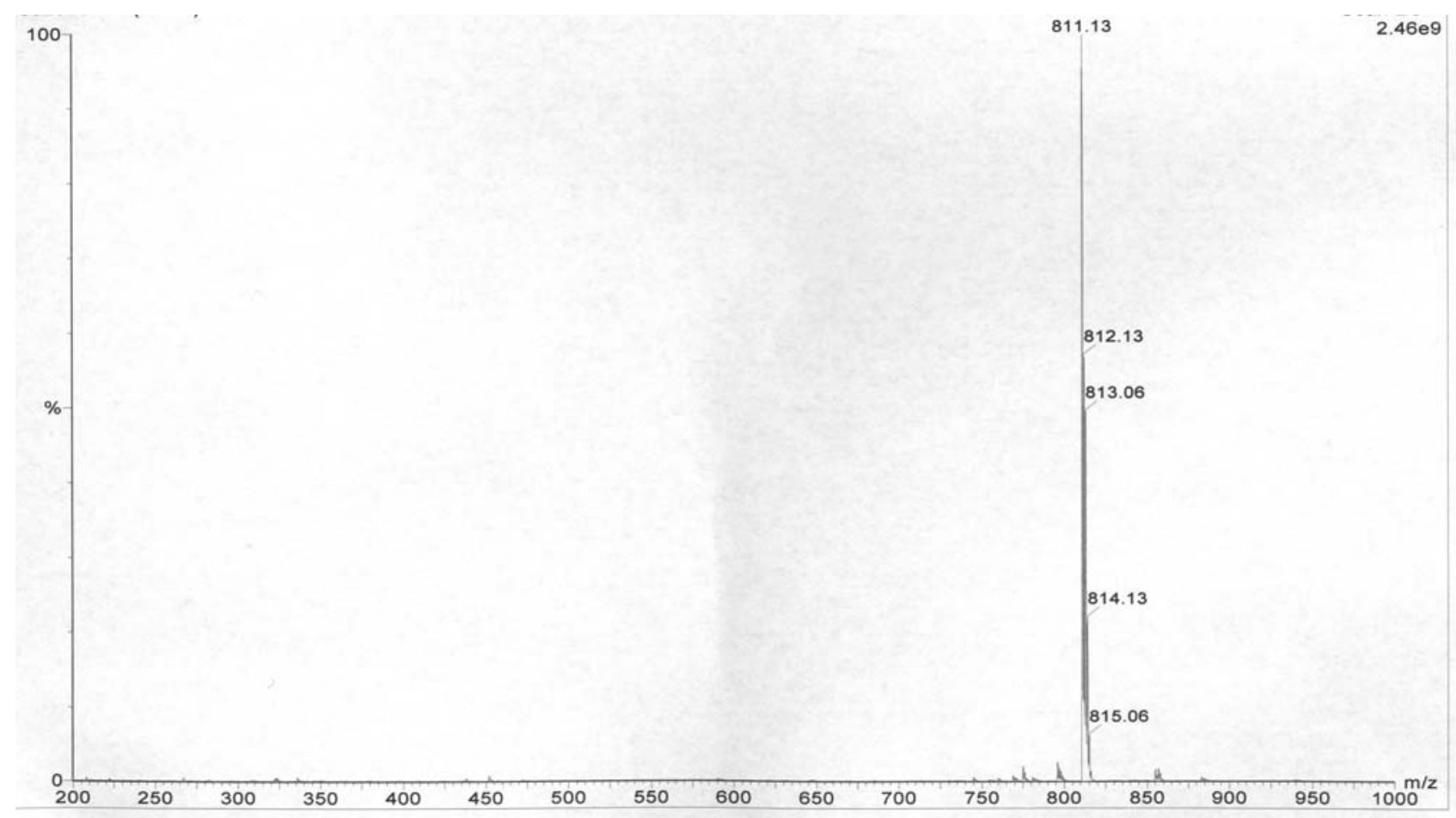


$\underline{\text { S4. MS/EI of acetonide protected CCG (11) }}$

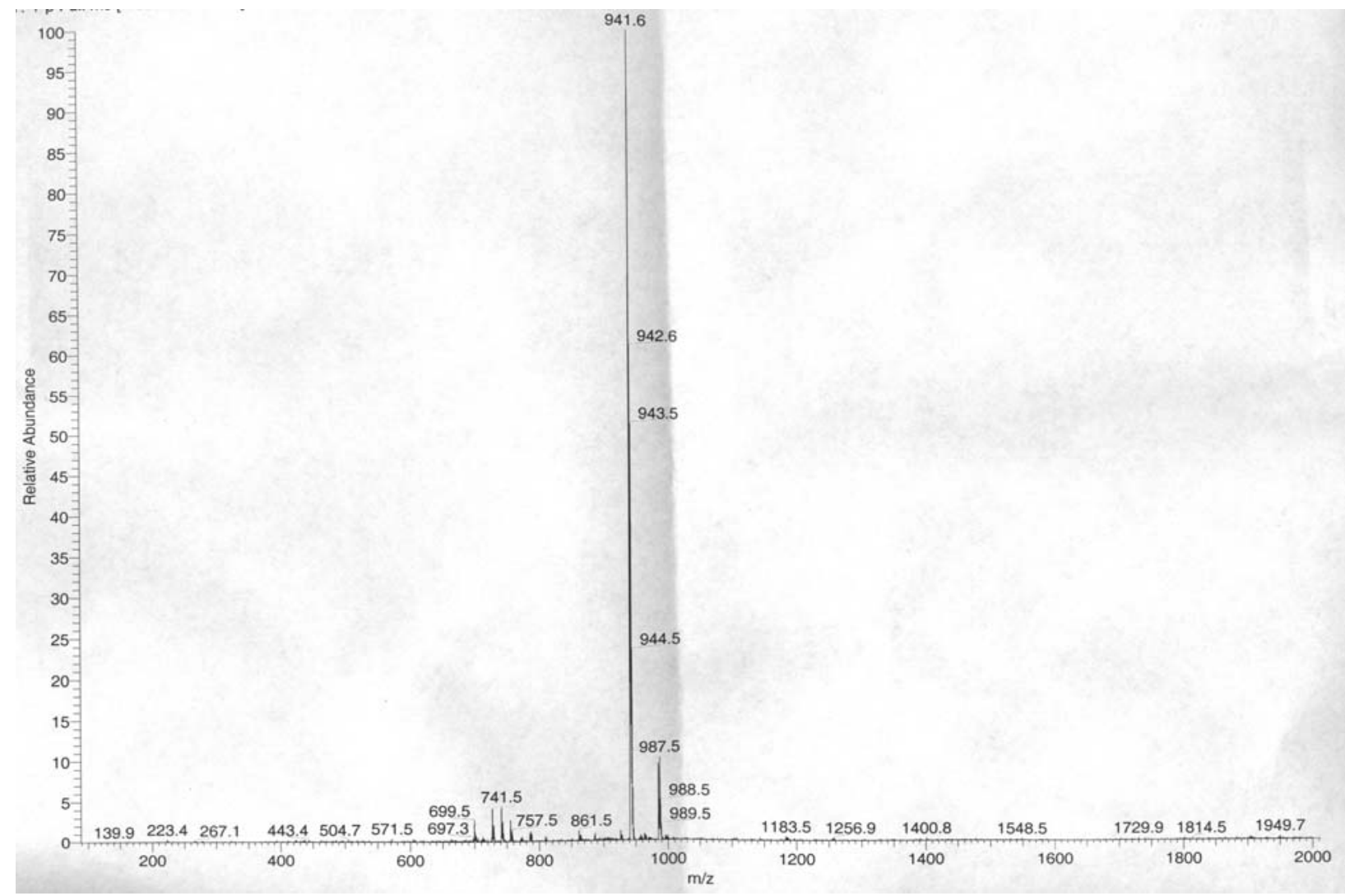

\section{$\underline{\text { S5. MS/EI of CCC (9) }}$}

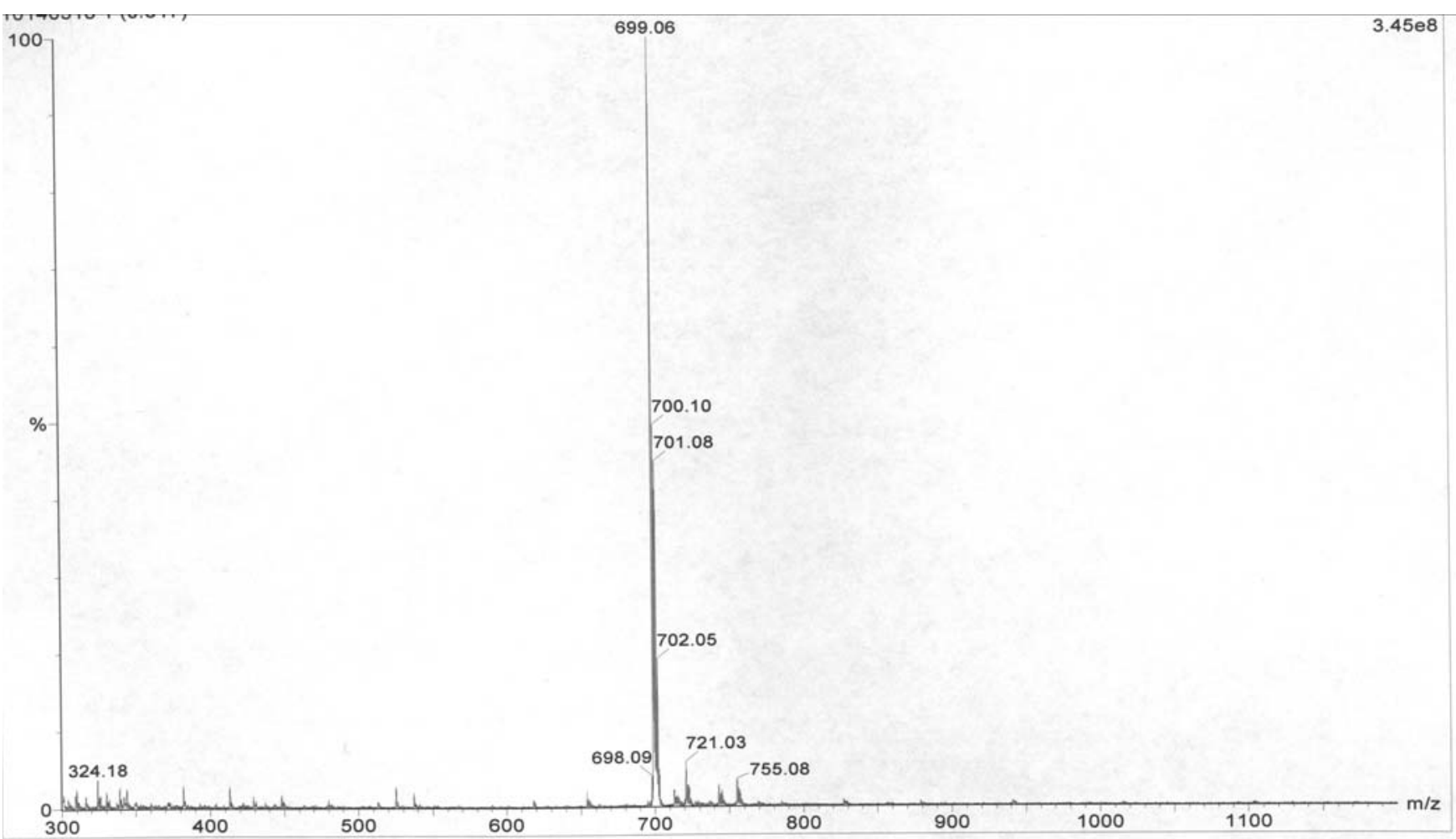




\section{S6. MS/EI of CCG 2}

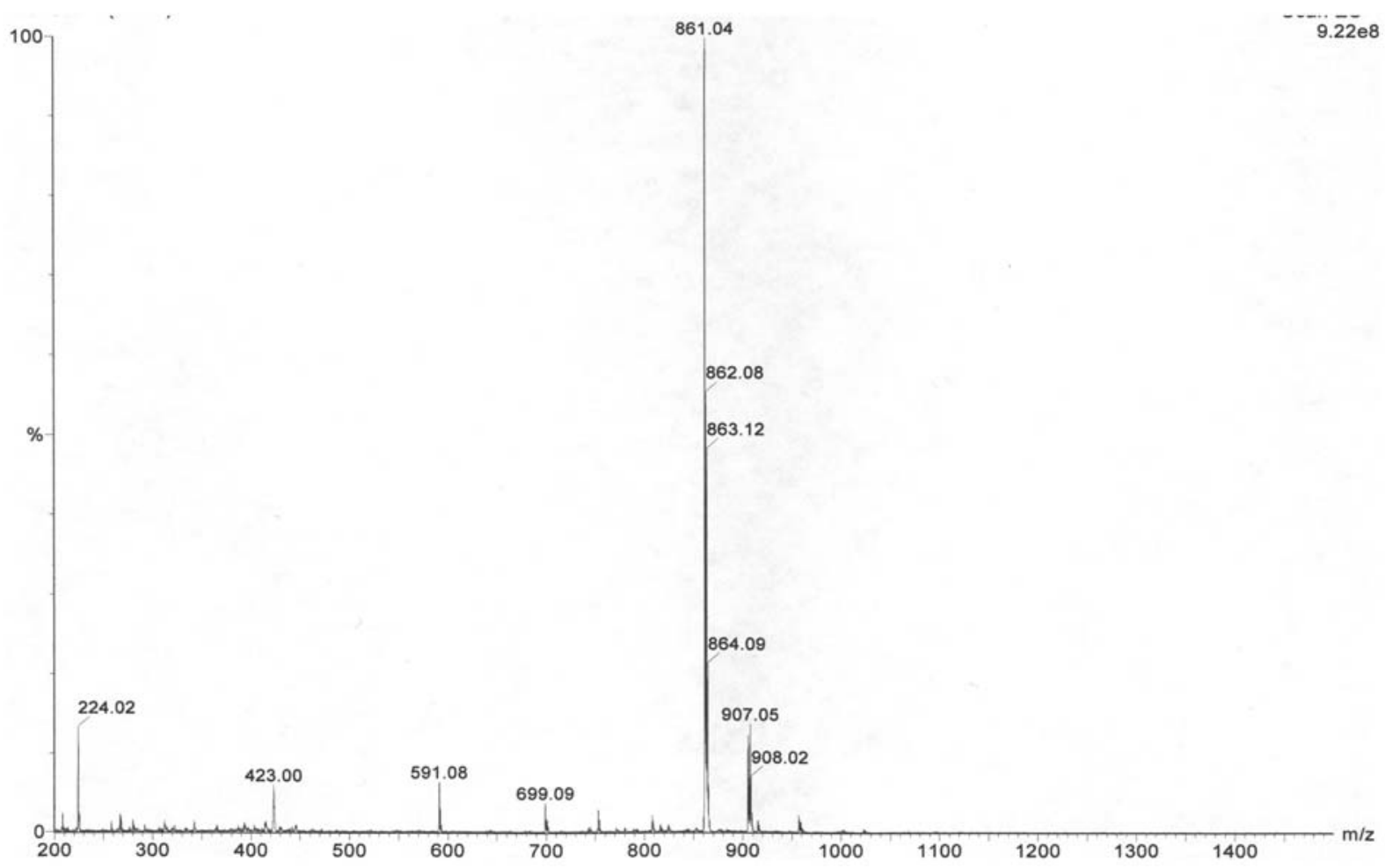

$\underline{\text { S7. Coexistence of cyclic form and hydrated linear gem diol form of acetonide protected CCG (11) from }}$ MS/EI study

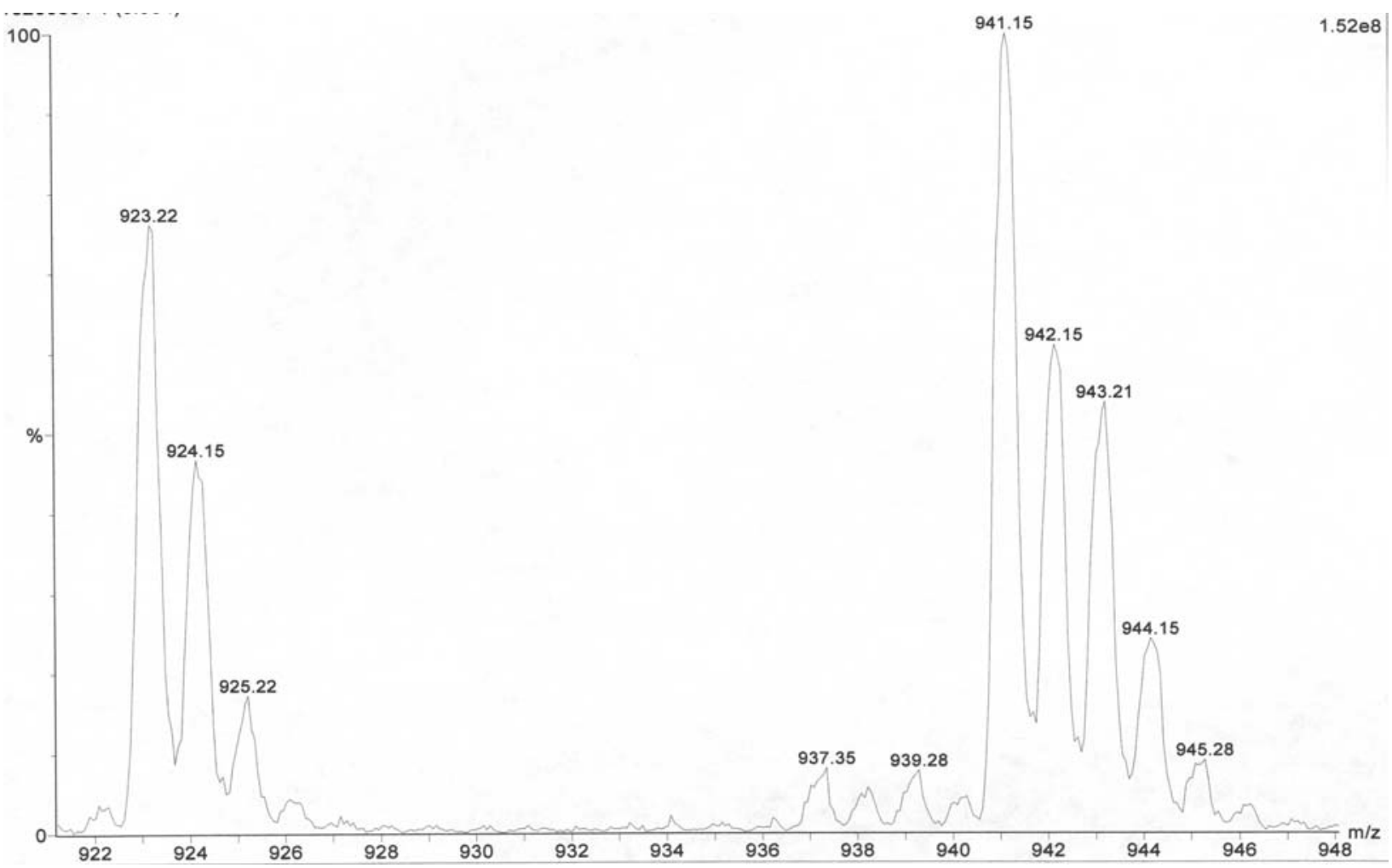




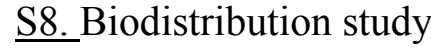

We employed a nominal $780 \mathrm{~nm}$ collimated solid state laser source to excite 2. A CCD camera (12 bit, 1024 x 1024 pixel, back illuminated) was equipped with the appropriate interference filter to capture the emitted photons at $830 \mathrm{~nm}$. All animal experiments were preformed in accordance with the Washington University Protocol for the use of laboratory animals. Nude mice were anaesthetized and injected with a $100 \mu \mathrm{L}$ of a $60 \mu \mathrm{M}$ solution of 2 . Time-sequence images of the mice were performed and the rodents were sacrificed at $24 \mathrm{~h}$ post-injection of the probe. The figure below shows the timesequence imaging and ex-vivo biodistribution in normal nude mice. The ex-vivo biodistribution was obtained after the animal was sacrificed at $24 \mathrm{~h}$ post-injection of the probe.

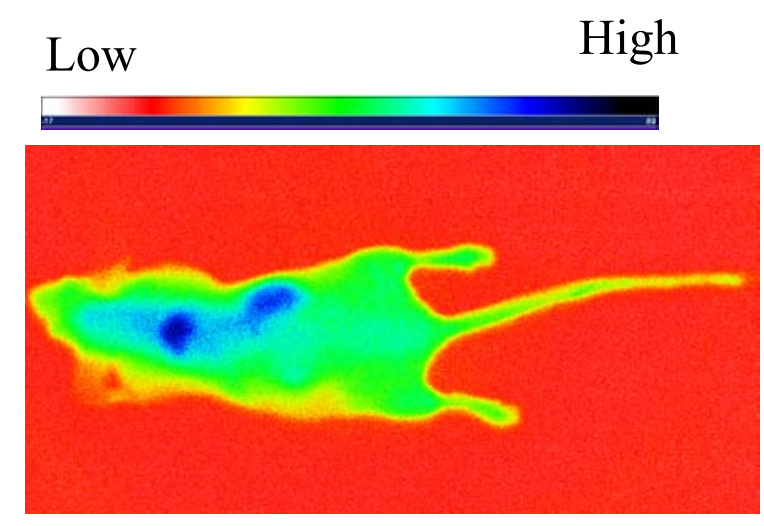

$1 \mathrm{~min}$

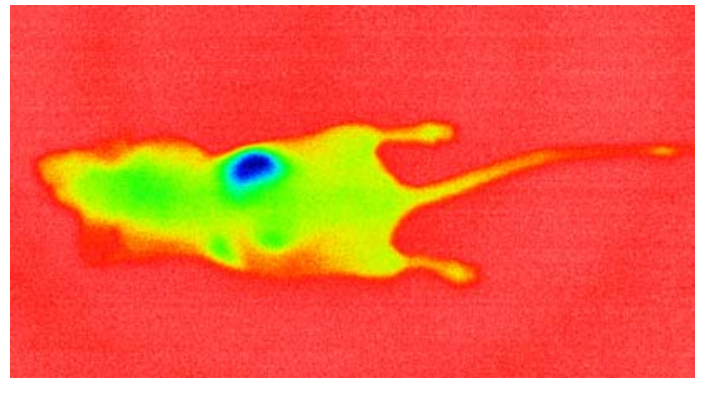

$10 \min$

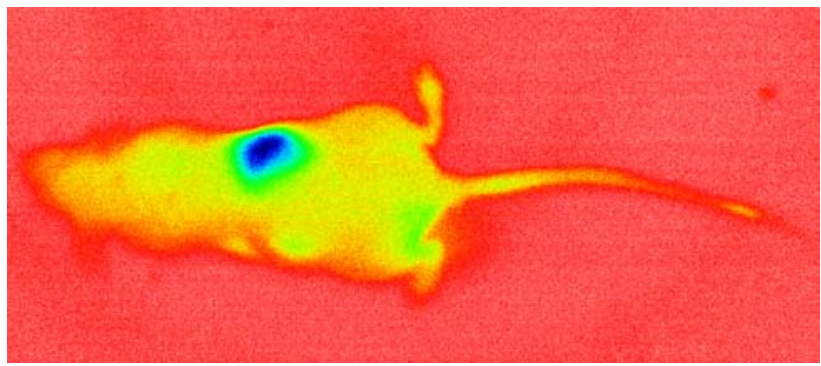

$30 \min$

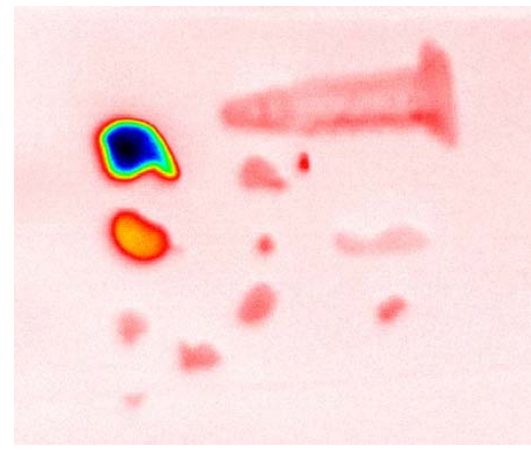

Major organ parts

Time sequence imaging of the biodistribution of CCC-galactose in nude mice. Oran parts were images ex-vivo at 24 h postinjection of the probe 